\title{
A condição do jovem no mercado de trabalho brasileiro: uma análise comparativa entre o emprego e o primeiro emprego (1999-2009)
}

\author{
Eliane Cristina de Araújo* \\ Maria de Fátima Garcia* \\ Izabel Aparecida Faustino ${ }^{* * *}$ \\ Elisangela Luzia Araújo ${ }^{* * * *}$
}

\begin{abstract}
RESUMO - Este artigo discute a inserção do jovem no mercado de trabalho brasileiro, especificamente aquele que busca uma primeira ocupação formal. $O$ objetivo é verificar a existência ou não de dificuldades adicionais para esse subgrupo, tendo em vista que se registram, tradicionalmente, elevadas taxas de desemprego para as faixas etárias mais jovens da população. Por meio da ferramenta de análise de séries de tempo investiga-se como o ciclo econômico afetou o emprego e o primeiro emprego no período 1999-2009. Os resultados obtidos sugeriram que, em períodos de estagnação econômica, o primeiro emprego reage mais fortemente, caindo com mais vigor do que o emprego total. Inversamente, nos períodos de recuperação, o primeiro emprego apresenta resposta mais lenta, relativamente ao emprego. Tais resultados sugerem que os trabalhadores do primeiro emprego estão em condição de adversidade no mercado de trabalho, o que remete para a necessidade de políticas públicas facilitadoras do acesso ao primeiro emprego, bem como promovedora de sua perenidade.
\end{abstract}

Palavras-chave: Emprego. Primeiro emprego. Crescimento econômico.

\section{INTRODUÇÃO}

A economia brasileira passou por profundas transformações a partir da década de 1990, momento em que a condução das políticas macroeconômicas esteve voltada para a estabilização de preços, bem como para a inserção do país na nova ordem econômica internacional. A crescente liberalização comercial, a desregulamentação do setor financeiro, a reformulação do papel do Estado e a reestruturação produtiva são as características que vão marcar essa fase e se constituir no norte que passa a orientar as decisões de política econômica.

As políticas macroeconômicas adotadas a partir de então impactaram negativamente a taxa de crescimento do PIB, cujo crescimento médio anual foi de apenas 2,3\%, entre 1990 e

\footnotetext{
* Doutora em economia pela Universidade Federal do Rio de Janeiro e professora adjunta do Departamento de Economia da Universidade Estadual de Maringá. Endereço eletrônico: elianedearaujo@yahoo.com.br.

** Doutora em economia pela Universidade Federal de Pernambuco e professora associada do Departamento de Economia da Universidade Estadual de Maringá. Endereço eletrônico: mfgarcia@uem.br.

*** Mestranda do curso de Pós-Graduação em Ciências Econômicas da Universidade Estadual de Maringá. Endereço eletrônico: izabel_faustino@hotmail.com.

**** Mestre em economia pela Universidade Estadual de Maringá. Endereço eletrônico: elisangelal_araujo@yahoo. com.br.
} 
1999, com reflexos sobre a taxa de desemprego da mão-de-obra que atingiu níveis inéditos na referida década, passando de 4,6\%, em 1990, para 8,2\% em 1999, configurando um quadro de deterioração das condições de trabalho. Na presente década, a taxa de desemprego continuou em elevação, atingindo o pico em 2003, quando alcançou 12,3\%. A partir de então, assistiu-se a uma ligeira melhora no que se refere ao crescimento econômico, o que refletiu favoravelmente sobre o mercado de trabalho e a taxa de desemprego ingressou em uma trajetória de queda continuada, registrando 7,9\% em 2008, com um sobressalto em 2009 (8,1\%), por conta dos efeitos da crise financeira internacional, deflagrada no ano anterior.

Estudiosos do mercado de trabalho apontaram como a principal causa do desemprego e da desestruturação o contexto de baixo crescimento econômico, que não foi capaz de gerar postos de trabalho em quantidade e qualidade requerida pela evolução da População Economicamente Ativa (PEA). ${ }^{1}$ Uma vez que o comportamento do emprego segue tradicionalmente uma trajetória igual ao do comportamento geral da economia, fica claro que a dinâmica macroeconômica influenciou negativamente o mercado de trabalho no período em questão.

Tendo tais fatores em conta, uma questão importante se impõe, qual seja, o fato de que o mercado de trabalho não reage de forma homogênea em resposta ao contexto macroeconômico, ou ainda, aos ciclos econômicos. Destaca-se um sub-grupo, dentro do mercado de trabalho, para o qual a intensidade ou a direção dos efeitos parece ocorrer de forma diferenciada: o jovem.

Isto pode ser analisado tomando-se como base os dados do Ministério do Trabalho que apontou que, em 2009, a faixa etária entre 18 a 24 anos era a que apresentava o maior percentual de desempregados, cerca de $30,57 \%$, duas vezes maior do que o observado para a faixa etária entre 40 e $49 \operatorname{anos}(13,44 \%$ ). A faixa etária de jovens entre 25 e 29 anos também apresentou uma taxa de desemprego elevada, 21,54\% no mesmo ano.

Além das taxas de desemprego elevadas para os jovens, os dados do Instituto Brasileiro de Geografia e Estatística (IBGE) apontam também que a parcela jovem no Brasil, ou seja, o grupo entre 15 e 29 anos, representava em 2008 aproximadamente 50 milhões de pessoas, cerca de $26 \%$ da população. Desse total, $30 \%$ pertenciam ao segmento considerado pobre (renda per capita inferior a meio salário mínimo), 53\% ao extrato intermediário (renda per capita entre meio e dois salários mínimos) e apenas $17 \%$ oriundos de famílias com renda per capita superior a dois salários mínimos, indicando que parcela significativa dessa faixa etária está condicionada às dificuldades de obtenção de renda e/ou à pobreza, necessitando inserir-se no mercado de trabalho o mais cedo possível.

1 Ver Pochmann, 2007, Alves (2000). 
Os dados em apreço permitem inferir que a inserção do jovem no mercado de trabalho parece ocorrer de forma diferenciada vis-à-vis a inserção dos demais trabalhadores e, sendo isso plausível, o que dizer daqueles que buscam um emprego pela primeira vez?

Nessa perspectiva, o objetivo desse artigo é analisar como o ciclo econômico afetou o mercado de trabalho brasileiro entre 1999 e 2009, comparando-se os resultados para o emprego e para o primeiro emprego, este enquanto um subgrupo daquele. A hipótese assumida é que o primeiro emprego comporta-se de forma diferenciadamente em relação ao emprego total, ou seja, apresenta maior sensibilidade à conjuntura econômica.

Para cumprir com este objetivo, o presente artigo encontra-se disposto do seguinte modo: após esta introdução, apresenta-se uma discussão sobre a problemática do jovem ingressante no mercado de trabalho. Em seguida, destacam-se as evidências de como o ciclo econômico influenciou o mercado de trabalho no período de 1999 a 2009. Finalmente apresenta-se uma guisa de conclusão.

\section{A QUESTÃO DO PRIMEIRO EMPREGO: A PROBLEMÁTICA DO TRABALHA- DOR INGRESSANTE NO MERCADO DE TRABALHO BRASILEIRO}

O emprego e o desemprego nas faixas etárias mais jovens da população são questões que vêm sendo objeto de preocupação não só dos governos, mas de toda a sociedade, tendo em vista as altas taxas de desemprego verificadas para esse público e as consequências delas advindas, numa realidade verificada não só no Brasil, mas em várias economias mundiais.

De acordo com Martins (2003), entre as diversas razões encontradas para explicar o maior desemprego entre os jovens, pode-se destacar: i) o baixo dinamismo econômico, que intensifica o fenômeno do desemprego entre os jovens, ii) a dificuldade de inserção ocupacional, devido a baixa qualidade de ensino, iii) a falta de experiência e/ou habilidades exigidas pelas empresas na hora da contração.

O baixo dinamismo econômico, de acordo com Pochmann (2000), é uma tendência que se verificou no Brasil no período a partir das décadas de 1980 e 1990, quando a maior incidência do desemprego entre os jovens se deveu às transformações econômicas e sociais vivenciadas pelo país. Na década de 1980 e 1990, nos anos de estagnação e/ou recessão, o desemprego entre os jovens aumentava, mas quando a economia voltava a recuperar o volume de jovens desempregados diminuía em uma proporção menor em relação ao volume de adultos desempregados. Já na década seguinte, sobretudo a partir de 2004, quando a economia ingressou em uma trajetória de recuperação econômica, não houve registro da diminuição das taxas de desemprego juvenil, apenas a estabilização da referida taxa (POCHMANN, 2000). 
Nessa mesma linha de raciocínio, Ribeiro e Juliano (2004), concordam que a taxa de desemprego (total e entre os jovens) segue o mesmo movimento, uma vez que a origem do desemprego dos jovens e das pessoas das demais faixas etárias é a mesma. Entretanto, observam que os jovens sempre apresentam uma taxa de desemprego mais elevada. Uma explicação plausível pode ser o fato de que, no início da retomada do crescimento econômico os empregadores preferem contratar os desempregados com experiência profissional e apenas quando tem-se a consolidação do crescimento, os desempregados com menos experiência são contratados. Em um cenário adverso, o congelamento das admissões recai fortemente sobre os jovens, que representam o maior percentual dos entrantes, indicando que, tanto no momento de expansão, quanto nos momentos de fraco dinamismo essa categoria apresenta as maiores taxas de desemprego.

No que se refere à educação, esta é tradicionalmente vista como um meio de melhorar os rendimentos do trabalhador. Entretanto, no Brasil, conforme Pochmann (2007), os constrangimentos do sistema nacional de ensino dificultam o avanço da escolaridade com qualidade, colocando obstáculos à ascensão social por intermédio do emprego. Tal fato produz um quadro geral de desânimo juvenil, influenciando, entre outros problemas, o exercício das atividades ilegais, estando as raízes da verdadeira crise na transição do sistema educacional para o mundo do trabalho.

Corroborando com essa ideia, Novaes (2010) destaca que, entre a população de 15 a 17 anos, que deveria estar no ensino médio, apenas $48 \%$ estão frequentando esta etapa, $44 \%$ ainda não concluíram o ensino fundamental e 18\% estão fora da escola, muitos pela própria necessidade do trabalho precoce, que antecede a saída da escola e tende a dificultar ainda mais as oportunidades futuras.

A questão do trabalho precoce e da escolaridade pode ser vista na Tabela 1, que apresenta o percentual de jovens entre 15 e 17 anos, segundo a renda familiar e a condição de estudo e trabalho.

De acordo a Tabela 1, pode-se constatar que uma parcela significativa dos adolescentes, entre 15 e 17 anos, trabalha e estuda, sobretudo na faixa de renda familiar per capita de até 2 salários mínimos, sendo os homens os que mais conciliam estudo com trabalho.

Para a faixa de renda per capita superior a 2 salários mínimos, o percentual de jovens que só estuda e não trabalha é o menor. Já para a faixa inferior a meio salário mínimo, verificase o maior percentual de adolescentes que não estuda e não trabalha, especialmente o gênero feminino.

Ao contrário da tendência dos países desenvolvidos que postergam o ingresso dos 
jovens no mercado de trabalho, visando a ampliação do nível de escolaridade, no Brasil a realidade é diferente. Para muitos jovens brasileiros ou concilia-se os estudos com o trabalho precocemente, ou ainda, renuncia-se aos estudos para contribuir com o orçamento familiar, sem esquecer-se de que uma parte relevante é marginalizada, sem acesso à escola e sem trabalho.

TABELA 1 - PERCENTUAL DE JOVENS ENTRE 15 E 17 ANOS, SEGUNDO A RENDA FAMILIAR PER CAPITA E CONDIÇÃO DE ESTUDO E TRABALHO

\begin{tabular}{|c|c|c|c|c|c|c|}
\hline $\begin{array}{l}\text { Renda per capita (em } \\
\text { salários mínimos) }\end{array}$ & \multirow[t]{2}{*}{ Anos } & Só estuda & $\begin{array}{c}\text { Trabalha e } \\
\text { estuda }\end{array}$ & Só trabalha & $\begin{array}{c}\text { Não estuda } \\
\text { e nem tra- } \\
\text { balha }\end{array}$ & Total \\
\hline & & Mu & lheres & & & \\
\hline \multirow{2}{*}{ Menor que $1 / 2$} & 1998 & 54 & 17 & 10 & 18 & 100 \\
\hline & 2008 & 66 & 14 & 5 & 15 & 100 \\
\hline \multirow{2}{*}{ De $1 / 2$ a menor que 1} & 1998 & 67 & 20 & 6 & 7 & 100 \\
\hline & 2008 & 68 & 16 & 5 & 11 & 100 \\
\hline \multirow{2}{*}{ De 1 a menor que 2} & 1998 & 79 & 14 & 3 & 4 & 100 \\
\hline & 2008 & 68 & 21 & 5 & 5 & 100 \\
\hline \multirow{2}{*}{2 ou mais } & 1998 & 88 & 8 & 2 & 4 & 100 \\
\hline & 2008 & 81 & 14 & 3 & 2 & 100 \\
\hline \multicolumn{7}{|c|}{ Homens } \\
\hline \multirow{2}{*}{ Menor que $1 / 2$} & 1998 & 40 & 31 & 19 & 10 & 100 \\
\hline & 2008 & 52 & 27 & 11 & 10 & 100 \\
\hline \multirow{2}{*}{ De $1 / 2$ a menor que 1} & 1998 & 56 & 29 & 11 & 5 & 100 \\
\hline & 2008 & 55 & 28 & 11 & 7 & 100 \\
\hline \multirow{2}{*}{ De 1 a menor que 2} & 1998 & 67 & 26 & 5 & 2 & 100 \\
\hline & 2008 & 55 & 32 & 9 & 4 & 100 \\
\hline \multirow{2}{*}{2 ou mais } & 1998 & 82 & 14 & 2 & 2 & 100 \\
\hline & 2008 & 75 & 19 & 4 & 3 & 100 \\
\hline
\end{tabular}

FONTE: IPEA/PNAD (2008).

A título de comparação, nos Países Nórdicos e na Alemanha o desemprego dos jovens é muito reduzido, chegando a ser menor que para outras faixas etárias. Isto ocorre porque parte de sua formação escolar é realizada no "chão de fábrica". Na Alemanha, por exemplo, existem disciplinas que são cursadas nas empresas e estas podem dar certificados de conclusão das mesmas. Dessa forma, a transição entre sistema escolar e mundo do trabalho apresenta-se menos problemática, traduzindo-se em menores taxas de desemprego. Conforme Ramos (2003), essa poderia ser uma saída para reduzir o desemprego entre os jovens, ou seja, as políticas públicas poderiam ter como foco a transição entre o sistema escolar e o mundo do trabalho e não o nível absoluto de estudos.

No que se refere à importância da experiência, Gonçalves e Monte (2008) destacam que os jovens brasileiros na atualidade, embora tenham um nível de escolaridade superior aos trabalhadores mais velhos, acabam inserindo-se em ocupações de baixa qualidade. Já os trabalhadores com experiência profissional possuem maior facilidade de inserção em atividades de maior produtividade e rendimento, ou seja, a inserção ocupacional dos trabalhadores ocorre de 
forma heterogênea, quase sempre favorável aos trabalhadores com maior experiência.

Os autores mostraram que os trabalhadores que buscam o primeiro emprego encontram maiores dificuldades para se inserir no mercado de trabalho, devido à falta de experiência. Segundo estes, no ano de 2005 foram admitidos 9.956.354 trabalhadores no mercado de trabalho formal do Brasil, dos quais 22,96\% foram trabalhadores admitidos por primeiro emprego e $77,06 \%$ foram admitidos por reemprego. Ao analisar a situação do primeiro emprego por regiões, verificaram que as regiões menos desenvolvidas do Brasil (Região Norte e Nordeste) contrataram um percentual maior de trabalhadores de primeiro emprego (37,36\%) quando comparadas às regiões mais desenvolvidas (Região Centro-Oeste, Sudeste e Sul). Tal fato segundo os autores está associado à dinâmica regional, especificamente ao surgimento de novas oportunidades de emprego, com menor concorrência e salários inferiores.

Monte et. al. (2005) analisaram a inserção ocupacional e a duração do estado de desemprego nas regiões metropolitanas de Recife e Salvador de duas classes de desempregados: a dos indivíduos que procuram o reemprego e a dos indivíduos que procuram o primeiro emprego. Para avaliar as características do indivíduo que interferem na sua inserção ocupacional utilizaram um modelo Logit bivariado, tendo como base os microdados da Pesquisa Mensal de Emprego (PME), de 2000 e 2001. Entre os resultados encontrados pode-se destacar que, em média, os indivíduos que já tiveram ocupação anterior têm suas chances aumentadas em relação àqueles que procuram o primeiro emprego e apresentam menores períodos de desemprego (25,6 meses contra 19,8 meses), nas regiões pesquisadas, demonstrando como a experiência é determinante na busca pelo emprego.

Diante do exposto, considera-se relevante a investigação mais detalhada do comportamento do emprego e do primeiro emprego no mercado de trabalho brasileiro.

\section{O CICLO ECONÔMICO E A SUA INFLUÊNCIA SOBRE O MERCADO DE TRA- BALHO: UM COMPARATIVO ENTRE O EMPREGO E O PRIMEIRO EMPRE- GO}

A presente seção trata das evidências empíricas sobre o modo como o ciclo econômico afeta o emprego como um todo e o primeiro emprego, busca-se explicitar como o ciclo econômico, que tem como proxy a produção industrial, afeta esses dois grupos do mercado de trabalho. O período estudado compreende desde janeiro de 1999 até dezembro de $2009^{2}$, quando há disponibilidade dos dados da pesquisa. São 127 observações mensais e as variáveis são

2 Tanto a série do emprego, quanto a série do primeiro emprego foram des-sazonalizadas pelo método X11 Arima. 
listadas a seguir: produção industrial (índice de produção física da indústria geral com ajuste sazonal); emprego, total de pessoas empregadas pela (Consolidação das Leis Trabalhistas - CLT), des-sazonalizada; primeiro emprego, total de pessoas admitidas pela primeira vez, sob o regime da CLT, dessazonalizada. A produção industrial é calculada pelo Instituo Brasileiro de Geografia e Estatística (IBGE) e o emprego e primeiro emprego pelo Cadastro Geral de Empregados e Desempregados (CAGED).

Sabendo que as variáveis são não estacionárias e possuem a mesma ordem de integração, calcularam-se as elasticidades de curto e longo prazo do emprego e do primeiro emprego em relação ao PIB industrial, sendo a de longo prazo calculada pelo procedimento de Johansen e a de curto prazo pelo método dos Mínimos Quadrados Ordinários.

TABELA 2 - ELASTICIDADE DO EMPREGO RELATIVA AO PRODUTO INDUSTRIAL, 1999 A 2009

\begin{tabular}{l|r|r}
\hline & Emprego & \multicolumn{1}{c}{ Primeiro Emprego } \\
\hline & 2.157433 & 1.833146 \\
Curto prazo & $(0.076288)$ & $(0.071526)$ \\
& {$[28.28019]$} & {$[25.62900]$} \\
& 2.632797 & 1.881508 \\
Longo prazo & $(0.27895)$ & $(0.08613)$ \\
& {$[9.43814]$} & {$[21.8458]$} \\
\hline
\end{tabular}

FONTE: Elaboração própria.

$[9.43814]$

NOTA: Entre parênteses o erro padrão e entre colchetes o teste $t$.

O cálculo das elasticidades de curto e longo prazo revela que tanto o emprego como o primeiro emprego são elásticos às variações na produção industrial, isto é, aumentos na produção industrial levam a aumentos mais que proporcionais no nível de emprego e primeiro emprego. Além disso, vale destacar que o primeiro emprego parece responder menos ao aumento da produção industrial que o emprego.

Prosseguindo na busca por evidências de como o ciclo econômico impacta o nível de emprego e o primeiro emprego, procedeu-se à divisão do período avaliado, de 1999 até 2009, em dois subperíodos: o primeiro, de 1999 até o final de 2003, caracterizado por relativa estagnação do PIB industrial e do emprego, e o segundo, com inicio em 2004 até o final de 2008, caracterizado por uma tendência de crescimento do produto e do emprego. ${ }^{3} \mathrm{O}$ objetivo consiste em investigar se o emprego e o primeiro emprego são mais ou menos sensíveis ao ciclo econômico em momentos de expansão ou estagnação da atividade econômica.

Para essa análise dividiu-se a amostra inicial em duas subamostras e calculou-se os resultados das elasticidades que se encontram nas Tabelas 3 e 4.

No período de relativa estagnação da economia observa-se uma sensibilidade mais

3 Optou-se por excluir o período da crise de 2008 por implicar uma mudança na trajetória de crescimento que as variáveis vinham seguindo. 
TABELA 3 - ELASTICIDADE DO EMPREGO RELATIVA AO PRODUTO INDUSTRIAL, 1999 A 2003

\begin{tabular}{l|r|r} 
& Emprego & Primeiro Emprego \\
\hline & 1,723485 & .2 .174857 \\
Curto prazo & $(0,240062)$ & $(0.257529)$ \\
& {$[7,179338]$} & {$[8.445105]$} \\
Longo prazo & 2.743409 & 4.224086 \\
& $(0.32949)$ & $(0.45877)$ \\
& {$[8.32620]$} & {$[9.20735]$} \\
\hline
\end{tabular}

FONTE: Elaboração própria.

NOTA: Entre parênteses o erro padrão e entre colchetes o teste t.

forte da variável primeiro emprego à queda na produção industrial, vis-à-vis a sensibilidade da variável emprego. Uma explicação plausível para isto encontra-se no fato de que, na fase descendente do ciclo, as empresas contratam menos e encontram no mercado um volume maior de trabalhadores experientes à disposição. Deste modo, os trabalhadores que anualmente adentram a PEA permanecem por mais tempo no segmento desocupado, de modo que este se torna mais encorpado nos períodos de estagnação. Em outras palavras, dado que nos momentos de estagnação da produção industrial, o primeiro emprego mostra-se mais sensível às variações no produto, o acesso ao primeiro emprego torna-se mais difícil.

TABELA 4 - ELASTICIDADE DO EMPREGO RELATIVA AO PRODUTO INDUSTRIAL: 2004 A 2008:8

\begin{tabular}{|c|c|c|}
\hline & Emprego & Primeiro Emprego \\
\hline \multirow{3}{*}{ Curto prazo } & 2.039004 & 1.422700 \\
\hline & $(0.190746)$ & $(0.162748)$ \\
\hline & $\begin{array}{r}{[10.68961]} \\
5.975498\end{array}$ & $\begin{array}{r}{[8.741745]} \\
1.697960\end{array}$ \\
\hline \multirow[t]{2}{*}{ Longo prazo } & $(1.39967)$ & $(0.17328)$ \\
\hline & {$[4.26922]$} & {$[9.79876]$} \\
\hline
\end{tabular}

FONTE: Elaboração própria.

[4.26922]

NOTA: Entre parênteses o erro padrão e entre colchetes o teste $t$.

Na Tabela 4 observa-se que o primeiro emprego reage menos que o emprego às variações no produto da indústria, tanto no que se refere à elasticidade de curto prazo como a de longo prazo. Isso implica que em momentos de crescimento econômico o primeiro emprego cresce menos em resposta a aumentos na produção industrial que o emprego como um todo.

Os resultados apresentados nesta seção permitem inferir que os trabalhadores dos extratos mais jovens estão sempre em condições adversas no mercado de trabalho, quer na fase ascendente, quer na fase descendente do ciclo. $\mathrm{Na}$ expectativa de que a maioria dos trabalhadores do primeiro emprego façam parte destes extratos mais jovens e levando-se em conta a falta de experiência como uma característica peculiar destes trabalhadores, poderia ser que para estes, as condições são ainda mais adversas.

Isto remete para a necessidade de se promoverem políticas públicas facilitadoras do 
acesso do jovem ao primeiro emprego, particularmente porque, com a tendência ao envelhecimento da população brasileira, é do trabalho dos jovens que dependem questões cruciais como a previdenciária, por exemplo. É verdade que a bandeira da problemática do desemprego entre os jovens já tem sido alvo de algumas ações de políticas públicas em seu favor.

Uma dessas ações consistiu na criação, em 2005, da Secretaria Nacional da Juventude, vinculada à Presidência da República, com o intuito de elaborar políticas públicas específicas para esse segmento.

Apesar disso, observa-se que a problemática dos indivíduos que galgam o primeiro emprego ainda demanda atenção. Embora seja reconhecido o fato de que o crescimento da economia seja o fator capaz de criar condições para a maior inserção do jovem no mercado de trabalho, esta pesquisa mostra que trata-se de uma condição necessária, mais não suficiente. A solução do problema passa pela adoção de medidas adicionais, a exemplo das políticas de investimentos em educação e escolaridade, maior qualificação, entre outras ações.

\section{GUISA DE CONCLUSÃO}

Este trabalho analisou teórica e empiricamente a relação existente entre crescimento econômico (cuja proxy utilizada foi a produção industrial) e o nível geral de emprego e a relação entre crescimento econômico e o primeiro emprego, este enquanto um subgrupo daquele.

Tal estudo foi norteado pela ideia de que a taxa de desemprego, sendo bastante superior para as faixas etárias mais jovens, independente do período considerado, responderia de forma diferenciada à flutuações econômicas, colaborando com a tese de que o primeiro emprego é mais sensível que o emprego em geral, seja pela falta de experiência dos jovens, seja pela falta de informação do empregador, entre diversos outras hipóteses.

Nesse intuito, a análise econométrica realizada demonstrou que as variáveis emprego e primeiro emprego responderam de maneira diferenciada às variações do ciclo econômico. $\mathrm{O}$ cálculo das elasticidades de curto e longo prazo revelou que tanto o emprego como o primeiro emprego são elásticos as variações na produção industrial, isto é, aumentos na produção industrial levam a aumentos mais que proporcionais no nível de emprego e primeiro emprego. Entretanto, o primeiro emprego parece responder menos ao aumento da produção industrial que o emprego.

Assim sendo, os resultados obtidos sugerem, para o período analisado, que em fases de relativa estagnação da atividade econômica o primeiro emprego reage mais fortemente, caindo com mais vigor do que o emprego como um todo. Inversamente, para as fases de recuperação da atividade econômica, o primeiro emprego apresenta baixa resposta à elevação da produção 
industrial.

Uma primeira explicação para o fato reside na ideia de que quando a economia cresce o emprego como um todo melhora, inclusive para aqueles que buscam uma primeira oportunidade. Já nas fases de recessão, dada as rigidezes de preços e salários trabalhadores mais antigos são poupados de uma demissão mais imediata, levando aos resultados sugeridos por esse estudo.

Diante do exposto fica claro que os trabalhadores do primeiro emprego estão em situação mais adversa que os demais, o que remete para a necessidade de se promoverem políticas públicas que facilitem o acesso ao mercado de trabalho, tendo em conta que essa é uma importante parcela da força de trabalho total.

\section{REFERÊNCIAS}

ANDRADE, G. O programa nacional de estímulo ao primeiro emprego de jovens. IPEA, 2005.

BALTAR, P. E. A.; HENRIQUE, W. Emprego e renda na crise contemporânea no Brasil. In: OLIVEIRA, C. A.B. et al (Org.). O mundo do trabalho: crise e mudança no final do século. São Paulo: Scritta, p. 605-618, 1994.

BARBOSA, Otávio. Primeiro emprego não obtém êxito e governo derruba projeto. Disponível em: <www.cofecon.org.br>. Acesso em: 08/04/2010.

CACCIAMALI, M. C. Globalização e suas relações com o mercado de trabalho. In: MARQUES, R. M. Mercado de trabalho e estabilização. São Paulo: Educ/Cadernos PUC, 1997.

DEDECCA, C. (2005). Notas sobre a evolução do mercado de trabalho no Brasil. In: Revista de Economia Política. n.25, v.1, jan-março de 2005.

GONÇALVES, M. F.; MONTE, P. A. do. Admissão por primeiro emprego e reemprego no mercado formal do Nordeste: um estudo mesorregional. ABEP, 2008. Disponível em: <http://www.abep.nepo.unicamp.br/encontro2008/.../ABEP2008_1313.pdf>. Acesso em: $01 / 2010$.

IBGE. Instituto Brasileiro de Geografia e Estatística, 2010.

IPEA - Instituto de Pesquisa Econômica Aplicada. Disponível em: <http://www.ipeadata.gov. br>. Acesso em: 02/04/2010.

KUPFER, D. Trajetórias de reestruturação da indústria brasileira após a abertura e estabilização. Tese (Doutorado em Economia). Instituto de Economia/UFRJ. RJ, 2008.

MARTINS, H. T. de S. A difícil transição: análise das trajetórias ocupacionais de jovens operários. Pro-Posições -Vol. 1 N25 (32) julho 2000. Disponível em: <http://mail.fae.unicamp.br/ proposicoes/textos/32-artigos-martinshhts.pdf>. Acesso em: 01/2010.

MEDEIROS, C. A. de. Industrialização e regime salarial na economia brasileira: os anos 60 e 70. Economia e Sociedade. Instituto de Economia/ UNICAMP, n.1, agosto de 1992.

POCHMANN, M. Situação do jovem no mercado de trabalho no Brasil: um balanço dos últimos 10 anos. São Paulo - fevereiro de 2.007. 
RAMOS, C. A. O Desemprego dos jovens: diagnósticos e políticas públicas. Mimeo, 2003. Disponível em: < http://www.carlosalberto.pro.br/arquivos/desemp_jovem.pdf $>$. Acesso em 12/03/2010.

REIS, M. C.; CAMARGO, J. M. Desemprego dos jovens no Brasil: os efeitos da estabilização da inflação em um mercado de trabalho com escassez de informação. Rio de Janeiro: IPEATexto para discussão n. 1116, Setembro, 2005.

TOKARSKI, M. Fim melancólico. Correio Braziliense. Disponível em: < http:/ / www.ipea.gov. br/003/00301009.jsp?ttCD_CHAVE=1919\&btImprimir=SIM>. Acesso em: 27/03/2007. 
